\title{
Lapita: The Australian connection
}

\author{
Ian Lilley
}

\begin{abstract}
Recent research in southern New Guinea, Torres Strait and north-eastern Australia suggests that Lapita users and possibly makers may have been present in regions hitherto believed to be beyond their reach. In New Guinea, the discovery of Late Lapita near Port Moresby has been augmented by findings of Late Lapita ceramics in the western Gulf of Papua. Southwest of the Gulf, undiagnostic locally made ceramics dating to around 2500 years ago are now known in the western Torres Strait. Other, somewhat younger, pottery has been found in the eastern Strait, some of it (or at least some of its constituents) from New Guinea. In addition, undiagnostic locally made surface pottery has recently been found on Lizard Island off Cape York Peninsula. This material is undated but hypothesised to be pre-colonial. Although Macassan fisherman left ceramics and other material remains on the northern Australian coast in the centuries just prior to European settlement, pre-colonial ceramics of any greater antiquity have never been found before in Torres Strait or on mainland Australia or its offshore islands. The proximity of the northern Australian find-spots to the new discoveries of Lapita in southern New Guinea, and the dating of at least some of the Torres Strait pottery to Late Lapita times, raises dramatic new possibilities regarding the course of prehistory in those areas.
\end{abstract}

\section{Introduction}

Archaeologists of both Australia and the Pacific conventionally exclude Australia from Oceania. Yet as I have observed elsewhere (Lilley 2000, 2006), a more inclusive view has been promoted for the last half-century by one of the region's premier professional journals, Archaeology in Oceania and its predecessor Archaeology and Physical Anthropology in Oceania. As the journal's long-time editor reminds us, Pleistocene low sea levels joined Australia and New Guinea (and Tasmania) as a single continent for more than 80 per cent of the region's human history (White with O'Connell 1982). One thus cannot consider this sizeable part of Oceanic archaeology without Australia, or indeed vice versa.

Now we have Lapita on Australia's doorstep on the Papuan south coast as well as locally produced, Late Lapita-aged and possibly Lapita-related ceramics in Torres Strait and tantalising finds of undiagnostic and still-undated but locally made pottery on Lizard Island, off Cape York. For so long, we thought that Lapita makers and users had skirted mainland New Guinea despite being within clear sight of it in places such as Siassi (Lilley 1988), and certainly had not come anywhere near Australia. Now we know they were not just close, but, given Lizard's proximity to Cape York, may even have landed on the Australian mainland (Figure 5.1). The Holocene 
histories of Australia and the Pacific did differ significantly, but these finds demonstrate that those divergent histories were not unconnected. Australia, including Torres Strait and the Great Barrier Reef islands, still technically remains outside the Lapita domain insofar as no diagnostic Lapita archaeology has been found on what is now Australian territory. Like the shared Pleistocene history, however, the fascinating possibilities flowing from the Papuan, Torres Strait and Lizard Island discoveries strengthen the case for routinely including Australia more centrally in our consideration of Pacific prehistory and for Australianists to be more outward-looking in their approaches to that continent's human past.

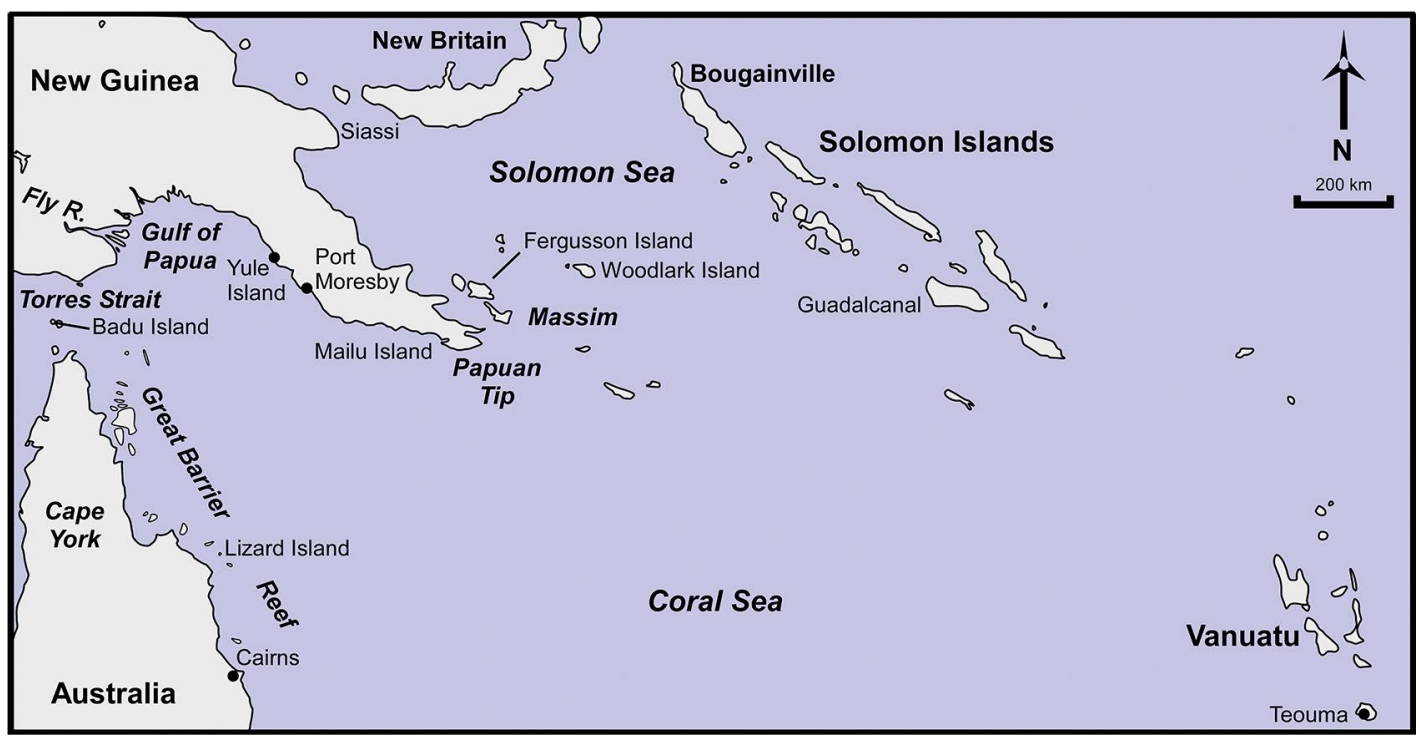

Figure 5.1. Australia, New Guinea and the Coral Sea.

Source: Michelle Langley.

\section{Background}

I do not propose to revisit the details of the debate about Lapita on the Papuan coast, or pottery in northern Australia. The former has been aired as exhaustively as possible at this stage (see David et al. 2004, 2011; McNiven et al. 2011; Skelly et al. 2014; and the special extended Forum section in Australian Archaeology 2012), and we eagerly await the detailed publications being prepared by the excavators. No new work has been done on the Torres Strait material since its initial publication (McNiven et al. 2006; see also Carter and Lilley 2008). Research continues on Lizard, but while some interesting archaeology is being produced from sites up to mid-Holocene in age (e.g. Aird et al. 2014; Fitzpatrick et al. 2014), at this point none of it has helped us get a better grip on the ceramics from the island (McNiven et al. 2014b). Analysis does indicate it was made locally (Tochilin et al. 2012) and the TL/OSL (thermoluminescence/optically stimulated thermoluminescence) dating of the ceramics that is currently in process could be invaluable in providing more detail (see also Lentfer et al. 2013).

For those relatively few researchers who work in Australia as well as the Pacific, these findings raise myriad questions about the course of deep human history in both regions. However, it would be fair to say that the new Papuan and northern Australian ceramics have really only exercised Pacific archaeologists to this point. Very few Australianists have engaged with the issues, unless they work in both regions. Even then, the issues that are raised are mostly about what such things might imply for Pacific rather Australian archaeology. In some ways this is understandable. Australia is a vast place, most of it is a very long way from Cape York and Torres Strait and, in 
the greater scheme of things, what may have happened in a remote part of the continent in the last few thousand years does not really make much more than a blip in a 65000 -year record of human occupation. I think, though, that there is more to it than that; something that goes to the heart of Australianist archaeology and its conception of the continent's place in the great sweep of human history.

On an anecdotal level, Australian archaeologists regularly complain amongst themselves about the dismissive or cursory way Australian archaeology is dealt with in global surveys of human prehistory. Yet for the most part, Australianists largely ignore the outside world, positing that the ancestors of today's Aboriginal Australians came, saw and conquered about 65000 years ago, and then, with the exception perhaps some 3000-5000 years ago of adopting the dingo, a canine that as a non-marsupial had to come from elsewhere, remained cut off from the outside world until seasonally visiting Macassan sea-slug gatherers from Indonesia began exploiting the northern coastline just before Europeans appeared on the scene. Extraordinarily, most general surveys of Australian prehistory do not even acknowledge more than in passing (if at all) that the continent was joined to New Guinea by dry land from the time of initial colonisation until the early Holocene (Hiscock 2008).

'So what?', Pacific archaeologists might ask. The possible presence or at least indirect impact of Lapita users and/or makers, or of pottery more generally, in the very far north-east of Australia really does seem to be more about the dynamics of history in the Pacific than it does the continent of hunter-gatherers', where, unlike the situations in say Jomon Japan or Mesolithic north-western Europe, no mainland people are known to have made or used pottery in prehistoric times. But is it? Contemporary migration theory and indeed current experience tell us that population movements are generally motivated by pull as well as push factors (e.g. Dorigo and Tobler 1983). That suggests that whatever dynamic might have been pushing Lapita pottery west along the Papuan coast, there was in all likelihood something pulling it in that direction as well.

\section{Push and pull processes}

First to the push factor(s). It seems probable that east-west developments spanning the Solomon Sea were implicated in the movement of Lapita along the Papuan coast, and conceivably also in the appearance of ceramics in Torres Strait and on Lizard Island. The original impetus for renewed archaeological work on Lizard was the late Bill Dickinson's (Felgate and Dickinson 2001) suggestion that petrographically exogenous Late Lapita found in the Solomons could have come from that island. That suggestion has since proven incorrect (Tochilin et al. 2012), but the material still came from west of the Solomons, specifically Muyuw-Woodlark Island in the Massim archipelago off the Papuan Tip. Combined with factors such as the presence of obsidian from Fergusson Island in the Massim in both the Reef Islands' Lapita site SE-RF-2 and at Teouma in Vanuatu to the south-east of the main Solomons (for the latter see Constantine et al. 2015) and in the Post-Lapita Oposisi site on Yule Island on the edge the Papuan Gulf far to the west, the Woodlark finding led Sheppard and colleagues (2015:74-77) to hypothesise the existence of an east-west interaction sphere that also facilitated the appearance of Late Lapita on the Papuan coast and the presence of Late Lapita ceramics in Torres Strait. Sheppard et al. do not mention the Lizard Island finds in this context, but Clark and Bedford (2008:70) recall in this same connection that Irwin (1992:143) predicted a generation ago that Lapita would be found in such locations (though not specifically Lizard), on the strength of a 100 per cent success rate of simulated one-way sailing voyages from the Solomons to northern Australia. 
Interestingly in this context, Richard Walter, a co-author on Sheppard et al.'s 2015 piece on Solomon Sea interaction, is also an author on a 2015 paper that demonstrates that 'many of the hawksbill turtles that nest in ... [a modern Solomon Islands marine sanctuary] forage in distant Australian waters' (Hamilton et al. 2015:1), including Torres Strait and on the Great Barrier Reef in the general vicinity of Lizard Island (Hamilton et al. 2015:7). On this evidence and Irwin's simulation results, it seems that moving between the Solomons and points west, not just across the Solomon Sea to the Massim but much further afield to the Papuan Gulf, Torres Strait and north-eastern Australian islands, is a relatively straightforward matter. Indeed, given what we know about turtle-hunting over the long term across the Pacific, including green turtles and hawksbills in Torres Strait (e.g. Allen 2007; Weisler and McNiven 2016), it is not far-fetched to suggest that developments in Sheppard et al.'s proposed Solomon Sea interaction sphere prompted people to follow turtles west and may have been one push factor that led to the appearance of ceramics in Australia's neighbourhood.

The foregoing push factors concern the Pacific but pull factors in this instance obviously concern Australia and its immediate neighbourhood. I propose that the emergence and intensification of McNiven's (McNiven et al. 2004, 2011) 'Coral Sea Interaction Sphere', which joins Barham's (2000; Barham et al. 2004) 'Torres Strait Cultural Complex' with emergent specialised marine economies on the north Queensland coast and islands, may have been part of a wider spiral of social and economic developments, which extended east along the Papuan coast and through the Massim to reach all the way to the Solomons. Such a spiral could have exerted a pull that amplified the effects of Late Lapita 'push' factors in prompting an Austronesian expansion west of the Massim and the Papuan Tip.

At the time that Barham and his colleagues were writing about the Torres Strait Cultural Complex, the oldest corrected dates for human occupation in Torres Strait were around $2500 \mathrm{cal}$. BP. This remains the oldest date for ceramics in the Strait, but it is several centuries younger than the more recently acquired Late Lapita dates for southern Papua. However, David et al. (2004) subsequently published dates for permanent occupation of Badu in the western Strait around 3500-3000 cal. BP. On that basis, and some years before they found Late Lapita near Port Moresby, David and his co-authors closely connected the settlement of Torres Strait to the appearance of Austronesian speakers and Lapita in southern Papua, hypothetically at the same time that Lapita was first expanding into Remote Oceania.

David and colleagues posited that the western Strait was settled from New Guinea around 3500 cal. BP owing solely to pressures (i.e. push factors) generated by Austronesian expansion. The Badu date of 3500-3000 cal. BP has more recently been complemented by dates of similar antiquity from elsewhere in the western Strait (Crouch et al. 2007; McNiven et al. 2006). We now know that settlement of the western Strait is some centuries older than the Late Lapita on the Papua coast. On the face of it, this means that insular Torres Strait was populated well before Lapita users and possibly makers made their way west along the Papuan coast. The 3500-3000 cal. BP date accords well with Barham et al.'s (2004:37) estimated date for 'the commencement of geological construction of beach accretionary and mangrove environments' across the Strait. Contra Barham and co-researchers' (2004:37) proposition that permanent occupation of the Strait was delayed until $2500 \mathrm{cal}$. BP and thus 'a cultural phenomenon rather than an artefact of geomorphological process', the Badu date suggests that people occupied the islands of the Strait as soon as they were suitable for human habitation after sea-level stabilisation. Indeed, Barham et al. $(2004: 40,57)$ indicated that pre- 2500 cal. BP dates were a possibility on high islands such as Badu. Thus, rather than emerging only from $2500 \mathrm{cal}$. BP, or some centuries after Lapita appeared in the Papuan coast, Barham's 'Torres Strait Cultural Complex' may well have been developing from at least 3500-3000 cal. BP, or some time before Lapita appears in the 
wider neighbourhood, at least on evidence so far. This timing is congruent with that proposed by McNiven in an unpublished 2011 conference presentation regarding the emergence of his wider 'Coral Sea Interaction Sphere', which he tied to the emergence of sandy cays in central Torres Strait from around $3000 \mathrm{cal}$. BP.

Where Badu's settlers came from 3000-3500 years ago is yet to be determined. We know people were living on or near the Papuan coast since at least the terminal Pleistocene (David et al. 2007), but there is nothing in the archaeological record on Badu to indicate that the island's first permanent settlers came from New Guinea rather than Australia. Barham et al. (2004:57; see also Barham 2000) favour late Holocene settlement of the Strait from the Papuan coast, initially through the islands of Saibai and Boigu. That is certainly a possibility, but there is no reason to suppose that people could not have been moving —in addition to or instead of from Papuanorth from Cape York via the high islands just off the Australian coast. David et al. (2004:74) posit this very situation for the intermittent use of Badu (and by implication other western Torres Strait islands) between 6000-3500 cal. BP. Yet they attribute the first permanent occupation from around $3500 \mathrm{cal}$. BP to 'an influx of people from the north or northeast', namely the Papuan coast (and in fact to Austronesians or 'nearby peoples culturally influenced by them'). Now we know that Lapita and thus probably also Austronesian speakers were not on the Papuan coast until many centuries later, it is more parsimonious to argue that the first permanent settlers of insular Torres Strait, at least in the western islands 3500-3000 cal. BP, were the descendants of the people who had been using the islands intermittently for millennia-from Australia.

Although they do not use the terms 'Coral Sea Interaction Sphere' or 'Torres Strait Cultural Complex' in this connection (and had not yet discovered Late Lapita on the Papuan coast!), McNiven et al. (2006:67) argued strongly a decade ago for just such a scenario. They observed that:

the dramatic increase in use of islands in the Western Group of Zenadh Kes [Torres Strait] adjacent to Cape York follows a broader trend of changes in Aboriginal land and sea use across various parts of northern Australia, especially Queensland.

Interestingly in relation to my earlier suggestion about turtles, McNiven and co-authors also noted that 'Barham (2000:300) makes the observation that "increasing abundance of dugong and turtle resources, as modelled here dating to after $3500 \mathrm{BP}$, provided some stimulus to movements offshore"'. They (2006:67) suggest that:

While this 'stimulus' (resource pull) was couched in terms of southward movement of Papuans, the stimulus could equally apply to a demographic expansion of local peoples already using the islands.

This proposal ties closely to hypotheses tendered more recently by McNiven et al. (2014a:121) in relation to use of the southern Great Barrier Reef islands. They argue that:

Expansion of island use commencing around 3000-3500 years ago is linked to population increases sustained by synchronous increases in marine resources ... The viability of risky offshore canoe voyaging was underwritten by two key high-return subsistence pursuits-hunting green turtles and collecting turtle eggs.

The hypothesis that the emergence of a Coral Sea Interaction Sphere joining the Torres Strait Cultural Complex to specialised marine economies on the north Queensland coast and islands exerted a pull across the Papuan Gulf rests on the proposition that any pre-Austronesian social and economic activity in the Torres Strait - Cape York/Great Barrier Reef region would have been linked to or at least have had reverberations through patterns of activity to the east, extending to a point, perhaps in the Port Moresby region, where they came into contact with westwardexpanding Lapita groups. This activity may have reached a level of intensity that made it an attractive prospect for exploration by Austronesian populations seeking opportunities for trade and exchange, prompted by developments in Sheppard et al.'s Solomon Sea interaction sphere. 
Alternatively, social and economic expansion in the broader region may have been diminished or halted by sociopolitical impediments, such as leadership patterns that precluded rather than encouraged continued growth. This could have set the scene for intercession by Austronesians who may have had a different leadership pattern, one conducive to maintaining or restarting growth. An environmental catastrophe or at least onset of difficult environmental conditions may also have disrupted or precluded social and economic activity in such a way that local systems could not recover quickly, again leaving the door open for opportunistic outsiders.

The idea that Late Lapita people in the Solomons Sea region may have been pushed and pulled towards Torres Strait and northern Australia by pressures or desires to strengthen their position in regional social and economic networks is more than just conjecture. It is not only suggested by the archaeology of relatively far-flung places in Papua New Guinea such as Port Moresby, Mailu and Siassi (e.g. Allen 1984; Irwin 1985; Lilley 1988), but is also documented directly by the ethnography from the verges of Torres Strait itself. Lawrence (1998:13) documents the movement in the second half of the nineteenth century of coastal Kiwai from the Fly estuary to the Papuan coast facing the Strait. There they established strategically located villages that allowed them 'to dominate the older established exchange movements ... [through] their dominance of maritime and fishing technology'.

\section{Concluding discussion}

To draw the foregoing threads together, we have on the one hand the proposition of Sheppard and his colleagues (2015) that an east-west interaction sphere emerged in Lapita times in the area of the Solomon Sea between the Massim/Papuan Tip and the main Solomon Islands chain. On the other hand, we have the argument from McNiven and co-researchers $(2006,2011)$ that the permanent occupation of Torres Strait and greatly increased use of Great Barrier Reef islands occurred in the same general period that Lapita appears in Island Melanesia but was effected from the Australian mainland as part of a wider upswing in island occupation around the continent but especially in the far north and north-east. My suggestion is that these two processes were linked, quite probably through a common focus on booming marine turtle populations, and thus provided the push and pull mechanisms that migration theory indicates were needed to bring Late Lapita settlement to the Papuan south coast.

The assertion that events and processes that first emerged on the Australian mainland and presumably remained connected to the mainland in various ways were in part responsible for a noteworthy eddy in the overall pattern of Pacific history remains to be more fully developed and then of course empirically tested. Nonetheless, I think it is important that we advance and explore such suggestions, rather than assume from the Australian perspective that Australia and the Pacific were entirely separate realms in the past, or at least after the postglacial formation of Torres Strait, and from the Pacific vantage point that the Austronesian-Lapita phenomenon had an internal dynamic strong enough to push it along without any need for local pull factors-and especially pull factors ultimately originating on the Australian mainland.

My arguments in this regard are conceptually consistent with efforts to (a) break down archaeologically unsustainable models that categorically separate Australia and the Pacific (and especially New Guinea); and (b) deconstruct connections between Lapita and (neo)colonialist notions regarding the superiority of Pacific peoples over Indigenous Australian peoples. The separation of Australia and New Guinea seems solidly cemented into the general consciousness of everyone including archaeologists. This state of affairs persists despite continued efforts to remedy the situation. Recently White (2011) revisited his 1971 work on 'New Guinea and Australia: The "Neolithic problem". He had done this, he wrote (2011:86): 
in the spirit of Gosden and Head (1999) who point out that 'the deepest divide we see [between Australia and New Guinea] is that imposed by European thought' (1999: 233), especially its division between hunter-gatherer 'savages' and agricultural 'barbarians'.

White (2011:86) outlined various approaches he thought offered us 'the best chance of reaching back into the real economic world of the past which ... may have been quite different to the one we think we know'. This present paper is a modest effort in the same vein, though more concerned with trade and exchange than agriculture. On the basis of present knowledge, there is no reason to prefer permanent settlement of Torres Strait 3500-3000 cal. BP from New Guinea rather than Australia. Indeed, as McNiven et al. argued in 2006, there are several empirically well-grounded reasons (now strengthened by the late dates for Papuan coast Lapita) to see things the other way around. Doing so allows us to remap our perceptions of the activities of Australian 'hunter-gatherers' in Torres Strait and north-eastern Australia from passive recipients of Melanesian enterprise to active players in processes that had impacts well beyond Australia’s shores.

As for connections between Lapita and neo-colonialism, I want to suggest that current views of Lapita on the Papuan coast seem to promote the idea that things Melanesian are inevitably superior to things Aboriginal Australian, a long-standing Antipodean version of European notions of 'ex oriente lux'. By this I mean that until recently, no one has suggested that events and processes in Torres Strait and north-eastern Australia may have been in any way connected with the movement of Late Lapita west from the Papuan Tip. Rather, the Neolithic Lapita juggernaut is seen to have simply 'rolled around the corner' under its own agriculturally generated momentum, to make its way west in much the same way as it moved south and east through Island Melanesia and out to Western Polynesia. Yet we know that there are almost always pull factors entailed in such situations. It makes sense in these circumstances to propose that developments that we know were occurring in Australia and spilling over into Torres Strait and the islands off Cape York were centrally implicated in the appearance of Lapita at Caution Bay and across the Gulf of Papua.

\section{Acknowledgements}

I intended to deliver this paper at the Lapita Eight meeting in Port Vila but was unable to attend. I presented a much abbreviated (and technologically undermined) version at the 2015 Society for American Archaeology symposium in honour of the late, great Bill Dickinson before he died with his boots on in Tonga. I am thankful to Stuart Bedford for insisting that I write it up for publication and then persisting with me to ensure I did it. Ian McNiven provided invaluable advice that knocked off the worst of the rough edges, and two reviewers made astute suggestions for improvement, but the final product is my responsibility.

\section{References}

Aird, S., S. Ulm and I. McNiven 2014. Aboriginal occupation and shellfish predation patterns during the Mid-to-Late Holocene at Lizard Island, north eastern Australia. In S. Ulm, G. Mate and J. Jerbic (eds), Culture, climate, change: Archaeology in the tropics: Conference handbook, p. 59. Australian Archaeological Association and Australasian Society for Historical Archaeology, Cairns.

Allen, J. 1984. Pots and poor princes: A multidimensional approach to the role of pottery trading in coastal Papua. In S. Van der Leeuw and A. Pritchard (eds), The many dimensions of pottery: Ceramics in archaeology and anthropology, pp. 406-473. University of Amsterdam, Amsterdam. 
Allen, M. 2007. Three millennia of human and sea turtle interactions in Remote Oceania. Coral Reefs 26:959-970. doi.org/10.1007/s00338-007-0234-x.

Australian Archaeology 2012. Forum: Recent Lapita pottery from the south coast of New Guinea. Special extended commentary. Australian Archaeology 75:1-24. doi.org/10.1080/03122417.2012.11681946.

Barham, A. 2000. Late Holocene maritime societies in the Torres Strait Islands, northern Australiacultural arrival or cultural emergence? In S. O'Connor and P. Veth (eds), East of Wallace's Line: Studies of past and present maritime cultures of the Indo-Pacific region, pp. 223-314. Modern Quaternary Research in Southeast Asia 16. A.A. Balkema, Rotterdam.

Barham, A., M. Rowland and G. Hitchcock 2004. Torres Strait bepotaim: An overview of archaeological and ethnoarchaeological investigations. In I. McNiven and M. Quinnell (eds), Torres Strait archaeology and material culture, pp. 1-72. Memoirs of the Queensland Museum Cultural Heritage Series 3(1). Queensland Museum, Brisbane.

Carter, M. and I. Lilley 2008. Between the Australian and Melanesian realms: The archaeology of the Murray Islands and consideration of a settlement model for Torres Strait. In J. Conolly and M. Campbell (eds), Comparative island archaeologies, pp. 69-83. Archaeopress, Oxford.

Clark, G. and S. Bedford 2008. Friction zones in Lapita colonisation. In G. Clark, F. Leach and S. O'Connor (eds), Islands of inquiry: Colonisation, seafaring and the archaeology of maritime landscapes, pp. 59-73. Terra Australis 29. ANU E Press, Canberra. doi.org/10.22459/ta29.06.2008.04.

Constantine, A., C. Reepmeyer, S. Bedford, M. Spriggs and M. Ravn 2015. Obsidian distribution from a Lapita cemetery sheds light on its value to past societies. Archaeology in Oceania 50(2):111-116. doi.org/10.1002/arco.5064.

Crouch, J., I. McNiven, B. David, C. Rowe and M. Weisler 2007. Berberass: Marine resource specialisation and environmental change in Torres Strait during the past 4000 years. Archaeology in Oceania 42:49-64. doi.org/10.1002/j.1834-4453.2007.tb00016.x.

David, B., I. McNiven, R. Mitchell, M. Orr, S. Haberle, L. Brady and J. Crouch 2004. Badu 15 and the Papuan-Austronesian settlement of Torres Strait. Archaeology in Oceania 39:65-78. doi.org/10.1002/ j.1834-4453.2004.tb00564.x.

David, B., A. Fairbairn, K. Aplin, L. Murepe, M. Green, J. Stanisic, M. Weisler, D. Simala, T. Kokents, J. Dop and J. Muke 2007. OJP, a terminal Pleistocene archaeological site from the Gulf Province lowlands, Papua New Guinea. Archaeology in Oceania 42:31-33. doi.org/10.1002/j.1834-4453.2007. tb00013.x.

David, B., I.J. McNiven, T. Richards, S.P. Connaughton, M. Leavesley, B. Barker and C. Rowe 2011. Lapita sites in the Central Province of mainland Papua New Guinea. World Archaeology 43(4):576-593. doi.org/10.1080/00438243.2011.624720.

Dorigo, G. and W. Tobler 1983. Push-pull migration laws. Annals of the Association of American Geographers 73(1):1-17. doi.org/10.1111/j.1467-8306.1983.tb01392.x.

Felgate, M. and W. Dickinson 2001. Late Lapita and Post-Lapita pottery transfers: Evidence from intertidal-zone sites of Roviana Lagoon, Western Province, Solomon Islands. In M. Jones and P. Sheppard (eds), Proceedings of the 2001 Australasian archaeometry conference, pp. 105-122. Research Papers in Anthropology and Linguistics 5. Department of Anthropology, University of Auckland, Auckland.

Fitzpatrick, A., S. Ulm and I. McNiven 2014. Stone arrangements in the Lizard Island Group: A study of indigenous seascapes in Northeastern Australia. In S. Ulm, G. Mate and J. Jerbic (eds), Culture, climate, change: Archaeology in the tropics: Conference handbook, p. 90. Australian Archaeological Association and Australasian Society for Historical Archaeology, Cairns. 
Hamilton, R., T. Bird, C. Gereniu, J. Pita, P. Ramohia, R. Walter, C. Goerlich and C. Limpus 2015. Solomon Islands largest hawksbill turtle rookery shows signs of recovery after 150 years of excessive exploitation. PLoS ONE 10(4):e0121435. doi.org/10.1371/journal.pone.0121435.

Hiscock, P. 2008. Archaeology of ancient Australia. Routledge, London.

Irwin, G. 1985. The emergence of Mailu. Terra Australis 10. Department of Prehistory, RSPacS, The Australian National University, Canberra.

Irwin, G. 1992. The prehistoric exploration and colonisation of the Pacific. Cambridge University Press, Cambridge. doi.org/10.1017/CBO9780511518225.

Lawrence, D. 1998. Customary exchange in the Torres Strait. Australian Aboriginal Studies 2 (1998):13-25.

Lentfer, C., M. Felgate, R. Mills and J. Specht 2013. Human history and palaeoenvironmental change at Site 17, Freshwater Beach, Lizard Island, Northeast Queensland, Australia. Queensland Archaeological Research 16:141-164. doi.org/10.25120/qar.16.2013.227.

Lilley, I. 1988. Prehistoric exchange across the Vitiaz Strait, Papua New Guinea. Current Anthropology 29:513-516. doi.org/10.1086/203669.

Lilley, I. 2000. So near and yet so far: Reflections on archaeology in Australia and Papua New Guinea, intensification and culture contact. Australian Archaeology 50:36-44. doi.org/10.1080/03122417. 2000.11681664 .

Lilley, I. 2006. Archaeology in Oceania: Themes and issues. In I. Lilley (ed.), Archaeology of Oceania: Australia and the Pacific Islands, pp. 1-28. Blackwell, Oxford. doi.org/10.1002/9780470773475.

McNiven, I. 2011. Did Lapita peoples move into Torres Strait? Unpublished paper presented at the Australian Archaeological Association Conference, Toowoomba.

McNiven, I., F. von Gnielinski and M. Quinnell 2004. Torres Strait and the origin of large stone axes from Kiwai Island, Fly River Estuary, Papua New Guinea. In I. McNiven and M. Quinnell (eds), Torres Strait archaeology and material culture, pp. 271-289. Memoirs of the Queensland Museum Cultural Heritage Series 3(1). Queensland Museum, Brisbane.

McNiven, I.J., W.R. Dickinson, B. David, M. Weisler, F. Von Gnielinski, M. Carter and U. Zoppi 2006. Mask Cave: Red-slipped pottery and the Australian-Papuan settlement of Zenadh Kes (Torres Strait). Archaeology in Oceania 41:49-81. doi.org/10.1002/j.1834-4453.2006.tb00610.x.

McNiven, I.J., B. David, T. Richards, K. Aplin, B. Asmussen, J. Mialanes, M. Leavesley, P. Faulkner and S. Ulm 2011. New direction in human colonisation of the Pacific: Lapita settlement of south coast New Guinea. Australian Archaeology 72:1-6. doi.org/10.1080/03122417.2011.11690525.

McNiven, I., M. Felgate, J. Specht, C. Lentfer, W. Dickinson, U. Proske, S. Haberle, J. Feathers, C. Harris, S. Aird, A. Fitzpatrick and S. Ulm 2014a. Enigmatic potsherds: A summary of field investigations at Mangrove Beach, Lizard Island, 2006-2013. In S. Ulm, G. Mate and J. Jerbic (eds), Culture, climate, change: Archaeology in the tropics: Conference handbook, p. 121. Australian Archaeological Association and Australasian Society for Historical Archaeology, Cairns.

McNiven, I., N. de Maria, M. Weisler and T. Lewis 2014b. Darumbal voyaging: Intensifying use of central Queensland's Shoalwater Bay islands over the past 5000 years. Archaeology in Oceania 49:2-42. doi.org/10.1002/arco.5016.

Sheppard, P., R. Walter, W.R. Dickinson, M. Felgate, C. Ross-Sheppard and C. Azémard 2015. A Solomon Sea interaction sphere? In C. Sand, S. Chiu and N. Hogg (eds), The Lapita Cultural Complex in time and space: Expansion routes, chronologies and typologies, pp. 63-80. Archeologia Pasifika 4. Institut d'archéologie de la Nouvelle-Calédonie et du Pacifique (IANCP), Nouméa. 
Skelly, R., B. David, F. Petchey and M. Leavesley 2014. Tracking ancient beach-lines inland: 2600-year-old dentate-stamped ceramics at Hopo, Vailala River region, Papua New Guinea. Antiquity 88(340):470_ 487. doi.org/10.1017/S0003598X00101127.

Tochilin C., W.R. Dickinson, M. Felgate, M. Pecha, P. Sheppard, F.H. Damon, S. Bickler and G. Gehrels 2012. Sourcing temper sands in ancient ceramics with U-Pb ages of detrital zircons: A Southwest Pacific test case. Journal of Archaeological Science 39:2583-2591. doi.org/10.1016/j.jas.2012.04.002.

Weisler, M. and I. McNiven 2016. Four thousand years of western Torres Strait fishing in the Pacific-wide context. Journal of Archaeological Science: Reports (7):764-774. doi.org/10.1016/j.jasrep.2015.05.016.

White, J.P. 1971. New Guinea and Australian prehistory: The 'Neolithic problem'. In D.J. Mulvaney and J. Golson (eds), Aboriginal man and environment in Australia, pp. 182-195. Australian National University Press, Canberra.

White, J.P. 2011. Revisiting the 'Neolithic problem' in Australia. Records of the Western Australian Museum Supplement 79:86-92. doi.org/10.18195/issn.0313-122x.79.2011.086-092.

White, J.P. with J.F. O’Connell 1982. A prehistory of Australia, New Guinea and Sahul. Academic Press, Sydney. 
This text is taken from Debating Lapita: Distribution, Chronology, Society and Subsistence, edited by Stuart Bedford and Matthew Spriggs, published 2019 by ANU Press,

The Australian National University, Canberra, Australia.

doi.org/10.22459/TA52.2019.05 